\title{
Unusual giant cell aortitis
}

\section{Tanina Rolfa, Piergiorgio Tozzi ${ }^{\mathrm{a}}$ and Salah D. Qanadlib,*}

a Department of Cardiovascular Surgery, University of Lausanne, Lausanne, Switzerland

b Cardiothoracic and Vascular Unit, Department of Radiology, University of Lausanne, Lausanne, Switzerland

* Corresponding author. Department of Radiology, CHUV-University of Lausanne, Rue du Bugnon 46, 1011 Lausanne, Switzerland. Tel: +41-79-5562112; fax: +41-21-3144488; e-mail: salah.qanadli@chuv.ch (S.D. Qanadli).

Received 24 March 2014; received in revised form 28 May 2014; accepted 10 June 2014

Keywords: Giant cell arteritis • Aortitis • Aortic valves • Cardiac computed tomography

A 76-year old patient was admitted for syncopal episodes, weight loss and fever. Laboratory findings revealed an inflammatory status. Computed tomography (Fig. 1) angiography showed a tumour-like process of aortic and mitral valves

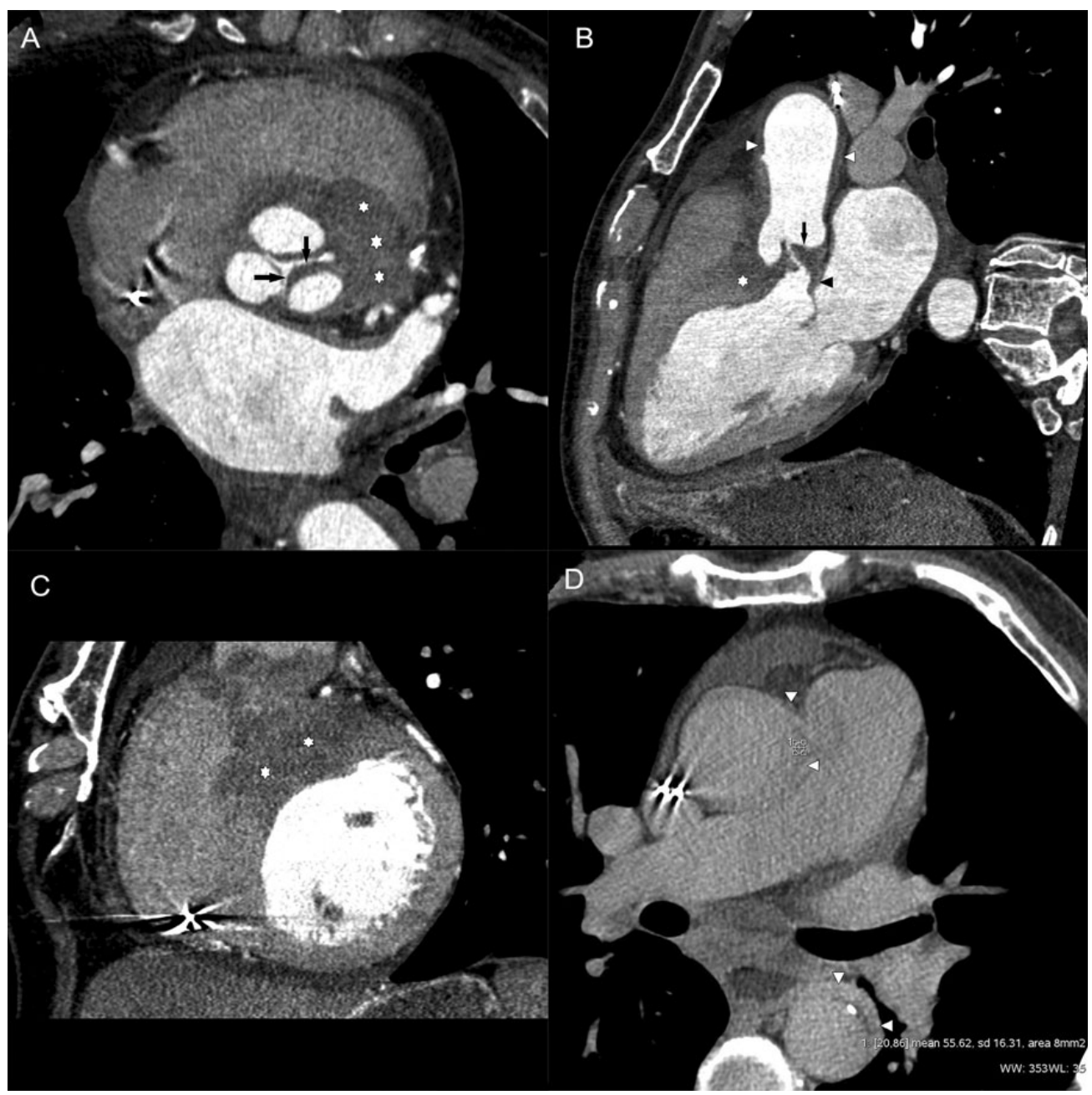

Figure 1: Cardiac computed tomography angiography. (A) Axial transverse view, (B) long axis view and (C) short axis view show well-defined pseudo mass involving the aortic valve (arrows), anterior mitral leaflet (black arrowheads) extended to the interventricular septum (stars) and the aortic wall (white). (D) 'Late enhancement' acquisition in the axial transverse plan that shows a clear enhancement of the aortic wall (attenuation value of 56 hounsfield units) (arrows). 


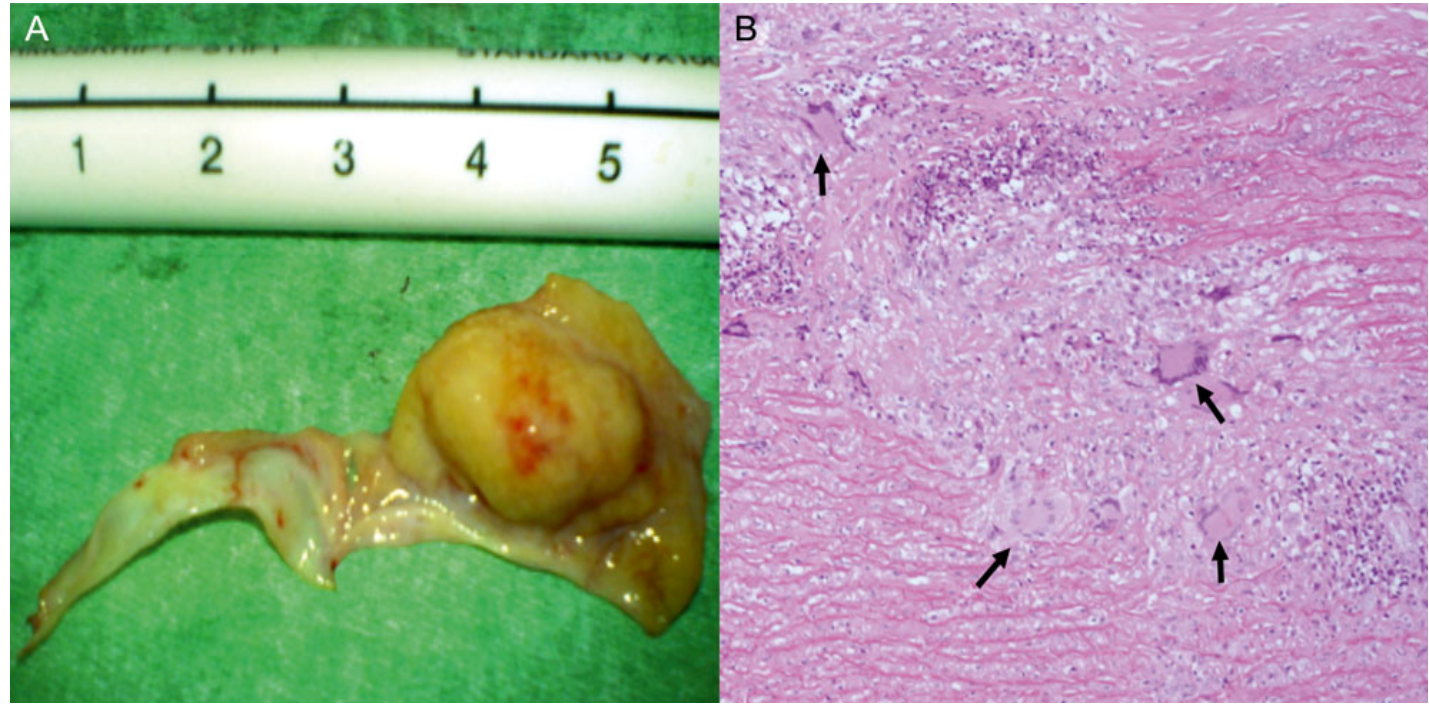

Figure 2: Pathology findings. (A) Excised aortic valve specimen during aortic valve replacement intervention. (B) Histology revealed granulomatous process with giant cells (arrows), necrosis and fibroinflammatory infiltrates highly suggestive of giant arteritis.

extended to the aortic wall. The pathology (Fig. 2) revealed granulomatous process suggestive of giant arteritis. The patient received aortic valve replacement, a pacemaker and corticosteroid therapy. 